\title{
Novos ambientes de aprendizagem para uma educação empreendedora: um estudo de analogias e metáforas utilizadas na implantação de núcleo de extensão acadêmica para uma instituição de ensino superior
}

\author{
Eduardo Bomfim Machado, GEMATEC, Faculdade Novos Horizontes, Brasil \\ Ronaldo Luis Nagem, GEMATEC CEFET, Brasil \\ Suryam Guimarães Lima, GEMATEC CEFET, Brasil
}

\begin{abstract}
Resumo: Os desafios da Educação Empreendedora ganharam novos contornos com o enorme desenvolvimento da internet e dos negócios virtuais. Com restrições de orçamentos, espaço físico e dificuldades de encontros presenciais em grandes centros urbanos, a utilização de ambientes virtuais de interação e acomodação de usuários em torno de projetos tem-se mostrado uma alternativa viável para concepção de novos espaços de aprendizagem. Com o uso de plataformas EAD de interação, uma IES de Belo Horizonte no Brasil dará um importante passo para o reforço da educação empreendedora junto ao seu curso de Administração. Com isso, este artigo pretende descrever como as analogias e metáforas interferem na percepção de potenciais usuários de um novo centro de ensino e extensão universitária, voltado para recepção e desenvolvimento de projetos de novos negócios, conhecido atualmente por Hotel de Projetos. Por meio de uma pesquisa "survey", o público alvo foi exposto a possíveis analogias e metáforas encontradas entre os dois objetos de estudo, que são os padrões de oferta relativos ao setor hoteleiro e os hotéis de projetos de novos negócios. Os resultados foram utilizados diretamente para decisões operacionais e ajustes nas formas de comunicação e divulgação, bem como nas melhorias a serem implementadas nesse novo centro de extensão. Além de contribuir com o meio acadêmico, disseminando dessa prática educacional de criação e manutenção de núcleos extensionistas como mecanismos alavancadores do aprendizado da educação empreendedora e de disseminação de ciências e tecnologia.
\end{abstract}

Palavras chave: educação empreendedora, analogias e metáforas, hotel de projetos, extensão universitária.

\begin{abstract}
The challenges of Entrepreneur Education had been taken to another level due the internet advances and virtual business. By the budget decreasing, small places and scheduling and meeting difficulties at the big cities, the use of cyberspace to join together users around proposals and projects rises as a possible alternative for new learning places also. This way, using a distant education platform systems a college of Belo Horizonte in Brazil will take a high step enhancing the Entrepreneur Education for its business school. This article aims to describe how the analogies and metaphors affect the perception of prospect users to a new extension and learning center designed to new business plans receiving, named Projects Hotel. Through a survey, the target was exposed to analogies and metaphors found between those objects, one was the different hotels offers, and another was the project hotels capable to help new business ideas. The results were helpful to make decisions to manage this new center, drove the marketing efforts of it among students and teachers and make a good improvement support. Those academic data were too helpful to spread this particular case of extension and learning activity as powerful leverage to entrepreneur education and spreading of science and technology.
\end{abstract}

Keywords: entrepreneur education, analogies and metaphors, project hotel, college extension.

Revista Internacional de Aprendizaje en la Educación Superior

Volume 2, Número 2, 2015, <http://sobrelaeducacion.com>, ISSN 2386-7582

(C) Global Knowledge Academics. E. Bomfim Machado, R. L. Nagem, S. Guimarães

Lima. Todos os direitos reservados. Permisos: soporte@gkacademics.com 


\section{Introdução}

$\mathrm{O}$ ensino do empreendedorismo em instituições de ensino superior (IES) tiveram início no Brasil em 1992 quando o então professor da Universidade Federal de Minas Gerais, Fernando Dolabela sistematizou um conjunto de conceitos e ferramentas úteis à formação e atuação de alunos dessa modalidade de ensino como empresários e protagonistas de novos negócios.

Os diferenciais entre essa abordagem brasileira, de outras metodologias de ensino da atividade empreendedora, tais como países da América do Norte ou Europa, estão relacionados com a grande variedade de áreas de conhecimento que podem ser capacitadas para lecionarem. Professores de outras áreas normalmente favorecem a percepção de detalhes dos diferentes setores e não apenas professores de administração (Dolabela, 2004).

Assim, tem-se os desafios normais da formação e capacitação dos futuros egressos do ensino superior para um mercado de trabalho cada vez mais dinâmico, que muitas das vezes apresentam avanços conceituais empíricos que não são rapidamente acompanhados pela academia. Ou ainda, uma necessidade característica da economia brasileira, que depende mais de categorias de empresas que promovam a inclusão econômica de grandes massas populacionais, do que propriamente grandes atividades empresariais que geram concentração de renda e poder, visto que essa parcela de população não possui capacitação para adesão a negócios de grande complexidade e uso de conhecimento.

Uma das possibilidades de ampliação de uma oferta de conhecimentos sobre a atividade empreendedora dentro da formação dos alunos de graduação em administração reside na concepção de um núcleo de ensino e extensão que proporcione aos alunos uma prática dos conceitos apresentados em sala de aula. Essa experiência de contato direto com uma realidade empreendedora sugere uma melhor fixação de conteúdo, bem como uma possibilidade de contribuição para o incremento do empreendedorismo, seja de projetos dos alunos, seja de projetos da comunidade, como a atividade extensionista sugere.

Existem diversas estruturas de fomento da atividade empreendedora vinculada a instituições de ensino superior, tais como pré-incubadoras, empresas junior, condomínio de projetos, incubadoras e mais precisamente os hotéis de projetos. Essa nova denominação constitui uma evolução da atividade de pré incubação, mas com objetivos mais precisos de consolidação da concepção de planos de negócios como objetivo final.

Dentro desse cenário, surge a situação problema vivenciada pelas instituições de ensino superior acerca da disseminação de conteúdos de empreendedorismo de forma mais dinâmica e alinhada com os interesses sócio econômicos dos seus alunos. Com isso tem-se a questão norteadora desse artigo: De que forma o uso de analogias e metáforas afeta a percepção de potenciais usuários de um núcleo extensionista de educação empreendedora?

Oferecer melhores condições de vivência prática para alunos do ensino superior pode tornar-se um diferencial de mercado para um posicionamento frente a outras ofertas similares, capaz de atrair a atenção de alunos ingressos. De tal forma, internamente, a adesão a um Hotel de Projetos, poderá contribuir com o desenvolvimento de novos negócios, sejam dos alunos ou da comunidade, o que vai de encontro a uma imposição do Ministério da Educação e da sociedade de uma maneira geral. (Brasil, 1996)

Mesmo assim, pode-se antecipar uma necessidade de melhor compreensão e favorecimento da adesão do público alvo de núcleos de ensino e extensão sobre a atividade empreendedora, haja vista a quantidade e especificidade de cada modalidade apresentada anteriormente. Com isso, para um caso de apresentação e contato com Hotel de Projetos eventuais esforços de comunicação tornar-seiam úteis para apresentar e direcionar a atenção de alunos que queiram participar de estruturas de fomento à atividade empreendedora.

O objetivo desse artigo é analisar como o uso de analogias e metáforas afeta a percepção do público alvo de um núcleo de ensino e extensão. Dessa forma, foram propostos os seguintes objetivos específicos: (i) organizar uma pesquisa bibliográfica com os temas centrais; (ii) aplicar uma pesquisa de campo aos alunos alvo; (iii) analisar os dados coletados sob à luz dos conceitos pesquisados. 


\section{Fundamentação teórica}

Inicialmente tem-se o empreendedorismo é definido por Dornelas (2001) como uma atividade econômica voltada para criação de novos negócios, com utilização de recursos e criação de valor, com eventuais situações de risco que envolvem grande parte dos esforços pessoais de um proponente ou grupo de proponentes.

Dentro dessa ótica, o autor também aborda as questões acerca do ensino da atividade empreendedora, uma vez que se percebe a importância da personalidade empreendedora em relação à qualidade e longevidade da sua ação. Juntamente com o crescimento do conhecimento acerca de como gerar, ou replicar novos negócios bem sucedidos Dornelas (2001) sustenta que o empreendedorismo pode aprimorar ainda mais determinados traços da personalidade de um gestor empreendedor úteis a uma abertura e crescimento de novos negócios.

Para favorecimento e amparo ao interesse empreendedor, e uma resposta à necessidade de apoio a projetos com esse enfoque, surge, desde a segunda metade do século XX, modalidades de estruturas de apoio, tais como as experiências da Universidade de Stanford em Palo Alto - CA (Dornelas, 2001); (Draper III, 2012).

Hisrich, Peters e Shephard (2009) apresentam um quadro de crescimento do ensino da atividade empreendedora por instituições de ensino superior, com aumento de carga horária e número de professores voltados para esse tema. Ainda que uma educação formal não seja determinante para a atividade empreendedora, os autores indicam que o nível de escolaridade é um fator muito útil para relacionamento com adversidades por parte dos empreendedores, além das etapas de seleção e aprimoramento de novos negócios.

Esse aumento na oferta de cursos foi acompanhado de um crescimento na pesquisa acadêmica, no oferecimento de disciplinas específicas da área, no aumento da concentração e especializações em empreendedorismo e de centros de atividade empresarial. (Hisrich, Peters e Shepherd, 2009, p.41)

Para Ferreira, Santos e Serra (2010) a importância do estudo do empreendedorismo está baseada em duas diretrizes. Uma diz respeito à possibilidade de aprimoramento de determinadas habilidades que são direcionadas à atividade empreendedora. Isso está retratado, quando da fala que um empreendedor não "nasce" efetivamente preparado, podendo ser esse moldado e capacitado, assim como gestores são formados em habilidades gerenciais que não possuíam antes da sua capacitação. A outra está relacionada com as demais informações necessárias à atividade empreendedora, que quanto melhores forem sua busca, sistematização e utilização, por parte do empreendedor, maiores seriam os impactos positivos da sua ação empreendedora.

$\mathrm{Na}$ concepção dos autores supracitados, o "ser empreendedor" está relacionado com algumas características, não apenas relacionadas com uma habilidade gerencial, mas, sobretudo, com certo senso de oportunidade que outros gestores possivelmente não desenvolveram ainda, o que os capacitam à proposição de novos negócios.

Aliás, atualmente, há outras ferramentas que auxiliam os empreendedores no desenvolvimento mais rápido e eficaz do negócio, visto que os empreendimentos de base tecnológica envolvem, normalmente, mais experimentação do que os negócios tradicionais. (Lopes apud Grando et al, 2012, p.495).

Na percepção de Grando et al (2012), as incubadoras de empresas, enquanto ambientes planejados e protegidos, estimulam a criação e desenvolvimento de micro e pequenas empresas, principalmente, dispondo para isso uma série de serviços de apoio para favorecer uma maturidade competitiva das empresas alvo.

Além das incubadoras, pode-se perceber uma subdivisão de um esforço de apoio à atividade empreendedora desde a consolidação desse formato apresentado. Dessa forma as atividades de Empresa Junior, pré incubadora, condomínio de projetos, entre outras possuem a capacidade de incremento conceitual e de qualidade a projetos empreendedores, favorecendo sua desde sua viabilidade, até a sua sustentabilidade. (Brasil Jr, 2012); (Fallgatter e Sena, 2004). 
(...) existem também muitas oportunidades de troca de informação, atualização e educação que podem ser feitas por meio de leituras de artigos e livros sobre os temas, que têm surgido com frequência cada vez maior. É extremamente importante que o potencial empreendedor ou os atuais empreendedores se relacionem com outros e troquem experiências e oportunidades. (Lopes apud Grando et al, 2012, p.508).

Nos ambientes educacionais de ensino superior, grande parte dos esforços do corpo docente está em ajustar, de acordo com perfis e demandas dos seus alunos, conteúdos e abordagens que devam estar alinhadas com preceitos de competências, tanto de uma maneira geral, quanto especificamente para o estudo de empreendedorismo, que eventualmente demanda um maior esforço didático (Goulart, Papa Filho, 2004)

Dentro de uma triangulação de áreas de conhecimento necessárias para consecução dessa pesquisa, Duit (1991) apresenta o conceito de analogia com uma comparação que, baseada em similaridades entre as estruturas de dois conceitos diferentes, sendo um conhecido (familiar) e outro desconhecido (não familiar).

Para Nagem (1997), com uma utilização de metodologia de ensino, por intermédio de analogia como prática docente, tanto para ensino médio, quanto para ensino superior, procura-se estabelecer uma relação entre conceitos já dominados pelos educandos com outros novos conceitos que devem ser ensinados. Esta relação se torna viável, quando se observam similaridades entre o conhecimento já dominado pelos alunos, o chamado conceito familiar e o conhecimento objeto de estudo, dessa forma considerado não familiar. O que reforça Nagem $(1997$, p.15) "as analogias expressam comparações e salientam similaridades com os objetos comparados, indicando claramente os termos comparados".

Já para Cachapuz (1989), professores em seu discurso expositivo podem utilizar com certa frequência e de forma espontânea, metáforas e analogias dentro de um esforço de tangibilizar temas e conceitos não familiares, contudo muito dessa prática não é sistematizada. $\mathrm{O}$ emprego do termo analogia suporta comparativos proporcionais e concretos, que extrapolam normalmente a esfera do exemplo prático, sendo também utilizadas quando do uso de construções lógicas e prováveis, graças ao uso de chaves de associação por meio de "semelhanças genéricas" (ABBAGNANO, 1999)

Com isso, tem-se a "Metodologia de Ensino com Analogias (MECA)" proposta por Nagem et al (2001), que apresenta um uso sistemático de analogias como recurso linguístico e didático. Tal método considera que as analogias favorecem processos de compreensão e de entendimento de conceitos por parte dos alunos:

O emprego de analogias busca, além da inovação pedagógica representada por uma forma dinâmica e adaptativa de se trabalhar a estruturação de conceitos com o aluno, uma aceitação crescente do recurso à intuição básica, tal como abordada por vários autores em reflexões epistemológicas acerca dos processos vitais e processos cognitivos (Nagem et al, 2001, p.197).

Para o autor supracitado, a MECA, primeiramente, está alinhada com o atendimento às necessidades dos aprendizes e não do corpo docente. Respeitando sua individualidade, os alunos podem perceber ganhos de aprendizagem com esse esforço de adaptação de repertório, mesmo tendo sua individualidade compreendida, tal singularidade demanda diferentes estratégias de aprendizagem e exibindo também diferentes habilidades ao solucionar problemas. Aproveitando-se que o ser humano é um ser social, a devida aceitação e posterior apropriação do contexto e da cultura na qual o sujeito (aluno) está inserido são também consideradas na evolução das competências intelectuais seja individualmente ou preferencialmente em grupos, por meio dessa construção de linguagens inovadoras.

É a experiência personalizada do eu estou conhecendo ou eu estou descobrindo uma nova forma de pensar, que necessita normalmente de conceitos-apoio e linguagens-apoio para que se consiga vivenciar a mudança. (Assmann, 1998).

Sendo as analogias assimiladas, processos completos de interiorização pelos aprendizes, favorecendo sua compreensão sobre novos conceitos por meio da transferência de relações conhecidodesconhecido (ou conhecido superficialmente), entende-se que as analogias, utilizadas no processo de cognição humana trazem consigo, tanto os conceitos-apoio quanto as linguagens-apoio. Estes conceitos-apoio e linguagens-apoio estão presentes nas práticas docentes convencionais e vivenciadas diariamente por professores e alunos, auxiliando aprendizes na assimilação de novos conceitos. 
A Metodologia de Ensino com Analogias (MECA) foi desenvolvida como resultado de estudos promovidos pelo GEMATEC - Grupo de Estudo de Metáforas e Analogias na Tecnologia, na Educação e na Ciência, do curso de Mestrado em Tecnologia do Centro Federal de Educação Tecnológica de Minas Gerais (CEFET-MG) Sua principal contribuição foi a estruturação de uma abordagem sistematizada da utilização de analogias como recurso cognitivo nos processos de ensino e de aprendizagem.

Nas considerações de Nagem et al (2001), uma proposta de utilização de um conjunto analogias como metodologia de ensino permite, ao mesmo tempo redimensionamento do uso e importância do repertório e o favorecimento da assimilação de novos conceitos. Isso ocorre na medida em que observação, reflexão e cognição podem, substituir, em parte, a atividade de tentativa de memorização simples do aluno frente aos novos conteúdos. A MECA procura fornecer apoio a professores e educadores por intermédio da sistematização da metodologia que está indicada no quadro 01 abaixo.

Tabela 1: Organização metodológica da MECA.

\begin{tabular}{|c|c|}
\hline Etapa & Objetivo \\
\hline $\begin{array}{l}1-\text { Área de } \\
\text { conhecimento }\end{array}$ & Definição da área específica abrangendo determinado conhecimento a ser trabalhado. \\
\hline 2 - Assunto & Conteúdo a ser abordado dentro da área de conhecimento. \\
\hline 3-Público & $\begin{array}{l}\text { Identificação da pessoa ou grupo a quem se deseja atingir com a analogia, detalhando } \\
\text { seu perfil. Esta etapa torna clara a preocupação quanto à adequação do veículo a fato- } \\
\text { res como idade, conhecimento, experiência prévia do aprendiz, assim como quanto à } \\
\text { sua relação com o conhecimento consensual e o contexto histórico em questão. }\end{array}$ \\
\hline $4-$ Veículo & $\begin{array}{l}\text { É a própria analogia, que utiliza o conhecimento prévio do aprendiz, proporcionando a } \\
\text { compreensão do objeto em estudo. }\end{array}$ \\
\hline $5-$ Alvo & É o conceito ou domínio que está que sendo ensinado ou aprendido. \\
\hline $\begin{array}{l}\text { 6- Descrição } \\
\text { da Analogia }\end{array}$ & $\begin{array}{l}\text { É a explicação do veículo que será utilizado no processo. É o processo no qual primei- } \\
\text { ramente se apresenta e explica o veículo e, somente depois passa-se a tratar o alvo. Tal } \\
\text { procedimento procura disponibilizar a analogia para o aprendiz em qualquer fase de } \\
\text { seu estudo, funcionando também como elemento motivador. }\end{array}$ \\
\hline $\begin{array}{l}7 \text { - Semelhan- } \\
\text { ças e diferenças }\end{array}$ & $\begin{array}{l}\text { Definição dos pontos relevantes para compreensão do alvo, sendo necessário o forta- } \\
\text { lecimento das semelhanças entre o veículo e o alvo. Deve haver uma explicação de } \\
\text { maneira objetiva das semelhanças e diferenças relevantes para a compreensão do } \\
\text { alvo. Na exploração da analogia, chama-se a atenção para a necessidade de se refor- } \\
\text { çar as semelhanças, que devem ser em número maior que o número de diferenças, a } \\
\text { fim de não se perder o sentido da analogia. Cabe ressaltar que as diferenças relevan- } \\
\text { tes também devem ser explicitadas, para que não ocorram transferências de caracte- } \\
\text { rísticas indesejáveis do veículo para o alvo em questão. }\end{array}$ \\
\hline 8-Reflexões & $\begin{array}{l}\text { É a análise em conjunto com os aprendizes, das limitações e da validade da analogia, } \\
\text { bem como da sua adequação ao conteúdo proposto. Neste tópico procura-se analisar, } \\
\text { junto aos alunos, a validade da analogia, suas limitações, verificando onde ela pode vir } \\
\text { a falhar, assim como sua adequação ao conteúdo proposto. Neste momento, torna-se } \\
\text { clara a proposta da metodologia, que é a de propiciar não apenas o entendimento do } \\
\text { conteúdo, mas também a atitude crítica e reflexiva. }\end{array}$ \\
\hline $9-$ Avaliação & $\begin{array}{l}\text { Trata da avaliação do grau de compreensão atingido pelo publico, propiciando a avali- } \\
\text { ação qualitativa da assimilação. Nesta etapa o aluno deve ser instigado no sentido de } \\
\text { elaborar sua própria analogia, propondo um veículo mais familiar às suas experiências } \\
\text { e levantar as similaridades e diferenças, explicitando dessa forma, sua compreensão } \\
\text { acerca do objetivo de estudo. Ressalta-se que a MECA sugere a professores e educado- } \\
\text { res uma estratégia que propicia a avaliação qualitativa da assimilação, baseada no grau } \\
\text { de compreensão atingido. }\end{array}$ \\
\hline
\end{tabular}

Fonte: Informação adaptada de Nagem et al, 2001, pp. 204-206.

Contudo, Nagem et al (2001) atenta para o fato de que a MECA condiciona a professores e educadores um formato de avaliação qualitativa da assimilação, baseada no grau de compreensão atingido, indicando que o item 9 do quadro acima. 
Cabe ao educador, então, interferir de modo a possibilitar que os aprendizes executem a tarefa por meio de atividades extra-classe. É preciso dar tempo para que o estudante internalize, reflita e busque suas respostas para as questões propostas. É importante considerar que a proposta de avaliação, no presente trabalho, destina-se a verificar o grau de compreensão e entendimento do aluno. A compatibilidade da analogia indica que houve, por parte do aluno, um entendimento e uma compreensão do conceito transmitido. Nagem et al (2001, p.206).

A Educação a Distância (EaD) tal como se conhece e se faz uso atualmente, por meio das Tecnologias Digitais da Informação e Comunicação (TDICs) e dos Ambientes Virtuais de Aprendizagem (AVA), é um fenômeno recente na educação. Não se pode afirmar, no entanto, que a EaD seja uma novidade. Para melhor compreender o processo dessa modalidade de educação, deve-se analisar como a literatura realiza sua conceituação. Moran (2002) a define da seguinte maneira: "Educação a distância é o processo de ensino-aprendizagem, mediado por tecnologias, onde professores e alunos estão separados espacial e/ou temporalmente" (Moran, 2002, p.1).

Assim, de acordo com o autor, a definição de EaD passa por questões como: processo de ensino-aprendizagem, uso de tecnologias e separação espacial e/ou temporal. Embora no Brasil a EaD tenha sido reconhecida oficialmente como modalidade pela Lei de diretrizes e Bases (LDB) em 1996, especificamente a Lei $\mathrm{n}^{\circ}$ 9394, de 20 de dezembro de 1996, tem-se registro de cursos que datam da década de 1930, com a Rádio-Escola Municipal no Rio de Janeiro e o Instituto Universal Brasileiro (IUB) em São Paulo (Dias e Leite, 2010).

Mugnol (2009), informa sobre a existência, desde o início do século XX, de cursos a distância que aconteciam por meio de correspondências. Os alunos eram, majoritariamente, pessoas que não haviam concluído os estudos no tempo formal da escola, sobretudo a básica.

A EaD, também denominada ensino a distância, não se trata de algo novo, inovador ou diferente. O que diferencia a EaD praticada hoje daquela praticada tempos atrás são os meios disponíveis e adequados em cada época". (Dias e Leite, 2010, p.09).

Pode-se compreender como meios disponíveis os aparatos tecnológicos utilizados na EaD. Embora seja comum a compreensão do termo tecnologia unicamente relacionado ao conceito digital, é importante fazer uma diferenciação entre as chamadas tecnologias dependentes e independentes.

Tecnologias independentes - são as que não dependem de recursos elétricos ou eletrônicos para sua produção e/ou utilização. Tecnologias dependentes - são as que dependem de um ou vários recursos elétricos ou eletrônicos para serem produzidas e/ou utilizadas (Pocho et al, 2012, p.10).

Isso compreendido, pode-se afirmar que a EaD já fez uso de diversas tecnologias em todo o seu processo histórico. Moran (2002) ainda colabora com a definição de $\mathrm{EaD}$ e cita diversas tecnologias que podem ser utilizadas nessa modalidade:

É ensino/aprendizagem onde professores e alunos não estão normalmente juntos, fisicamente, mas podem estar conectados, interligados por tecnologias, principalmente as telemáticas, como a Internet. Mas também podem ser utilizados o correio, o rádio, a televisão, o vídeo, o CD-ROM, o telefone, o fax e tecnologias semelhantes (Moran, 2002, p.1).

A tecnologia digital em muito influenciou para a expansão da EaD. Afirmam Grossi et al (2013: "É o caso da internet que chegou visivelmente no início da década de 80 e vem viabilizando a implementação de cursos à distância permitindo o encontro de professores e alunos não somente em salas de aula como também através de redes (...)" (Grossi et al, 2013, p. 381).

Os mesmos autores refletem sobre os AVA, plataformas virtuais que podem ser utilizadas para o ensino: "vários ambientes virtuais de aprendizagem têm sido utilizados no contexto educativo, como tentativa de romper as paredes da sala de aula e possibilitar a ocorrência da aprendizagem de forma mais significativa e dinâmica" (Grossi et al, 2013, p. 379).

Santos (2012) faz uma interessante descrição sobre a plataforma Moodle e da relação da tecnologia com a educação. A plataforma, para o autor, tem uma característica ampla e pode ser utilizada no contexto do ensino a distância, presencial e semi presencial. Além disso, não subutiliza da tecnologia, 
mas possibilita que ela seja utilizada de maneira a possibilitar a troca de conhecimento e a interação entre professor/alunos e alunos/alunos e a construção, por parte de cada um, do próprio conhecimento.

Grossi, Costa \& Moreira (2013) chamam a atenção para a necessidade de uma equipe multidisciplinar para melhor explorar as ferramentas tecnológicas disponíveis e as diversas formas de interação entre os sujeitos que participam da EaD. De acordo com os autores:

Nessa perspectiva, pode-se considerar de grande importância uma configuração institucional adequada aos cursos a distância, juntamente com as tecnologias para a mediação dos conteúdos. Assim, se percebe a necessidade da atuação conjunta de diferentes atores, tais como: professor formador; professor conteudista, professor pesquisador; tutor presencial, tutor virtual (tutor a distância), coordenador de curso ou coordenador pedagógico, coordenador de pólo, pedagogo e designer instrucional. (Grossi, Costa e Moreira, 2013, p.660).

A relevância do papel do tutor e as interações desse com os outros atores do contexto são ressaltadas por Grossi; Costa \& Moreira (2013). Para eles, a tutoria tem a responsabilidade de "assegurar as comunicações bidirecionais entre tutor-aluno e aluno-professor, comunicações que são essenciais para que ocorra a construção do conhecimento" (Grossi; Costa e Moreira, 2013, p.661).

Considerando seu longo processo histórico, sua forte presença atual e suas possibilidades futuras, a EaD mostra-se como uma importante modalidade de ensino, que deve ser constantemente analisada e discutida, afim de que seja realizada de maneira que o ensino-aprendizagem seja bem sucedido.

Já o Turismo é um setor composto por diversas atividades, entre elas a Hotelaria, que está diretamente relacionada à demanda turística. Hotéis, pousadas, albergues e hostels prestam serviços a turistas e compõem o segmento hoteleiro (Mello e Goldenstein, 2011).

De acordo com Wada e Camargo (2006, pág. 56), "hotel é uma palavra de origem francesa que designava residência senhorial" No Brasil, quando começaram a surgir hotéis, esses tinham como modelos casas nobres. Hoje acontece o contrário. Os hotéis não buscam assemelhar-se a moradias, mas têm a arquitetura inovadora e moderna. De acordo com os autores, "busca-se o aproveitamento das condições paisagísticas que o terreno oferece, estudam-se as condições de insolação etc. e suas repercussões e influências no comércio e na habitação" (Wada e Camargo, 2006, p.56)

A hotelaria demanda muita mão de obra, empregando, assim, uma grande quantidade e diversidade de profissionais, desde a construção até a operação do empreendimento. Possuindo ainda uma diversificação de ofertas para atendimento de uma grande variedade de clientes, que podem ser agrupados em segmentos distintos, seja por condições econômicas, sejam por característica de empreendimento (Mello e Goldenstein, 2011).

Mello e Goldenstein chamam a atenção para a sazonalidade, característica marcante do setor turístico e hoteleiro. A oscilação das demandas, ou seja, os períodos de maior e menor procura de serviços hoteleiros definem essa sazonalidade.

A elevação da taxa de ocupação nos períodos de baixa temporada é um objetivo perseguido pela hotelaria em todo o mundo. A promoção do turismo de negócios por meio de congressos, seminários e feiras é uma estratégia comumente empregada (Mello e Goldenstein, 2011 p.13).

\section{Metodologia}

A pesquisa realizada descreveu a opinião dos potenciais usuários desse núcleo de ensino e extensão. De uma maneira qualitativa, os respondentes apresentaram suas respostas ao questionário proposto, em um formato normalmente conhecido como survey, ou em uma tradução aproximada: enquete.

Para uma rápida preparação e aplicação de questionários, optou-se pelo uso de formulários eletrônicos que foram disponibilizados a uma listagem de e-mails do público alvo selecionado. Tal decisão aproximou a realidade operacional do núcleo de ensino e extensão que se servirá de um ambiente Moodle, como esperou-se que a adesão dos respondentes fosse maior.

As questões relativas à opinião foram construídas com uma escala intervalar entre 0 e 5 que condizia os respondentes a manifestarem sua opinião em concordância a temas levantados sobre sua percepção do objeto hotelaria de negócios, temas relativos a hotelaria de projetos e eventuais analogias entre ambos. Sempre com a mesma métrica, essas escalas foram úteis para comparativo das respostas 
pelos métodos abaixo indicados, bem como puderam ser associadas a outras escalas de descrição de amostra, como temas discriminantes, tais como gênero, faixa etária e interesses profissionais.

Quanto à amostragem, essa envolveu a identificação e organização de uma listagem de endereços eletrônicos do corpo discente, sobretudo daqueles alunos dos períodos adjacentes do $5^{\circ}$ período do curso de administração. Período no qual existirá o direcionamento de atividades junto ao referido núcleo. Em um universo de 124 alunos houve 79 questionários validados Tida como uma amostragem intencional os resultados devem ser entendidos como não probabilísticos.

O formulário apresentado possuía questões de caracterização do respondente em função do item 3 da abordagem da MECA, bem como a exploração dos itens 4, 5 e 7 da mesma. Como forma de obtenção de respostas sobre: público, veículo, alvo e semelhanças e diferenças, respectivamente.

Para tratamento dos dados coletados, utilizou-se de conteúdos de estatística descritiva com frequência, moda, e desvio padrão para correlação e montagem de conglomerados das respostas recebidas.

\section{Análise dos resultados}

Os resultados da pesquisa são apresentados, descrevendo 4 dimensões: (i) a instituição; (ii) os respondentes; (iii) as analogias; (iv) reflexões. Essa subdivisão tem correlação com parte das 9 dimensões da MECA que foram utilizadas para a construção do formulário e de sua análise. Não foram utilizadas, contudo, as dimensões "Área de Conhecimento" e "Assunto", devido ao recorte de conteúdo desse artigo e de seu embasamento teórico, bem como a dimensão "Avaliação", pois não foi analisada uma prática metodológica completa de ensino, como sugere a MECA.

\section{A instituição}

A IES que foi utilizada como objeto de pesquisa atua no mercado de ensino superior no município de Belo Horizonte capital do Estado de Minas Gerais e a quinta maior cidade do Brasil. Inaugurada há 14 anos, ela conta hoje em dia com três unidades, possuindo cerca de 3.000 alunos distribuídos em 6 cursos de graduação bacharelado e 5 cursos de graduação tecnológica, além disso é uma das poucas faculdades que oferece regularmente cursos pós graduação na modalidade mestrado acadêmico.

Tal estrutura consolidada na área das ciências sociais aplicadas, não possuía até então uma das exigências do MEC para os cursos superiores em Administração, a necessidade de se ter um centro ou núcleo de práticas extensionistas, fato que foi implementado no primeiro semestre de 2015, a exemplo de outros cursos como o Direito e a Contabilidade que já possuem suas estruturas de atenção para tais práticas

Um dos principais recursos empresariais que tornaram essa implementação complexa foi a escassez de espaço físico para acomodação das atividades propostas a um Hotel de Projetos. Dado a isso, a opção de utilização de plataforma de EaD para esse fim, não apenas trata-se de uma decisão de consistência conceitual, mas de uma decisão alternativa para tornar viável essa estrutura.

O conteúdo programático de Inovação e Empreendedorismo é apresentado aos alunos de Administração no $5^{\circ}$ semestre e foi a partir desse conteúdo que tem-se, tanto uma base conceitual para a adesão e utilização desse núcleo implementado, por parte dos alunos, quanto uma necessidade de vivência prática desses alunos como forma de dinamização dos conteúdos aprendidos. Além disso, tem-se que os alunos, já na metade da sua formação, possuem capacidade de orientação de profissionais autônomos e interessados em abrirem seus negócios, com conteúdos básicos da administração já vistos e dominados até aqui, tais como: contabilidade, sistemas de informação, matemática financeira, entre outros.

\section{Mulheres e homens maduros $x$ empreendedorismo}

A caracterização dos respondentes passou por três grupos de variáveis que servem como discriminantes para compreensão dos padrões de respostas obtidas.

Primeiramente, foram arguidos quanto ao seu gênero. $43 \%$ dos respondentes é do sexo feminino, quanto $57 \%$ do sexo masculino. 
Quanto à faixa etária, pode-se observar que a moda é de 30 anos acima com $28 \%$ dos entrevistados. Tendo $21 \%$ dos entrevistados entre 26 a 30 anos; $17 \%$ entre 22 e 25 anos; outros $21 \%$ entre 19 e 21 anos; e os demais, 13\%, com até 18 anos. Esse tipo de subdivisão pode ser reflexo direto dos agrupamentos por períodos que acomodam os alunos por séries semestrais.

Mas o dado que mais chamou a atenção dentro dessa amostra, com predominância masculina e certa maturidade para um perfil esperado de graduação, é a baixa perspectiva de atividade empreendedora, uma vez que apenas $16 \%$ dos respondentes afirma que está cursando a graduação em administração com objetivo de abrir seu próprio negócio, com uma preferência para negócios individuais do que coletivos. $12 \%$ e $4 \%$ respectivamente do total de respondentes. O maior interesse na graduação está em ter um emprego público 33\%, seguido de emprego em empresa privada $29 \%$.

\section{As analogias}

Nessa etapa, foi sondada a familiaridade dos respondentes com o Veículo proposto representado pela oferta de hotéis empresariais, voltados para hospedagem de pessoas de negócios, atividades empresariais e demandas relacionadas com empresários e funcionários que viajam com esse propósito.

Assim, pode-se perceber que os alunos respondentes possuem baixa experiência em relação a esse tipo de oferta, com $68 \%$ indicando que nunca viajaram a negócios, contra $15 \%$ que indicaram que o fazem com mais frequência. Essa informação está diretamente relacionada com os objetivos da graduação dos alunos e também com a sua própria situação de estudantes e habitantes locais.

A partir dessa constatação, buscou-se uma correlação entre os padrões de respostas que exploram, ao mesmo, tempo essa baixa experiência mas sem se afastar da opinião pessoal do que venha a ser um hotel empresarial e seu desempenho estimado, com as demais variáveis utilizadas para dinamizar o Alvo dessa analogia. Foram utilizadas questões, por exemplo, sobre a eficácia de uma estrutura de hotel empresarial no favorecimento de encontros, negociação de profissionais, dos diferentes tipos de serviços e acomodações com esse fim e da necessidade de reservas para essa classe de hotéis.

Em contrapartida, houve outro grupo de questionamentos direcionados para busca de eventuais semelhanças e diferenças entre os padrões de oferta de hotéis empresariais e os padrões de oferta de um hotel de projetos.

Dessa forma pode-se constatar que o público respondente masculino, compreende que a estrutura de um hotel empresarial realmente favorece a dinamização de negócios $(0,997)$; que há diferentes tipos de acomodações $(0,951)$ e que os objetivos de um hotel de projetos compreendidos $(0,899)$.

Além disso, esse grupo de respondentes reconhece a utilidade de um hotel de projetos, mesmo sem uma experiência prévia $(0,757)$, bem como conseguem estabelecer uma semelhança entre esses dois padrões de ofertas $(0,859)$, muito embora entendam que o gerenciamento de ambos é diferente $(0,976)$ o que de certa forma é muito coerente com um entendimento de uma diferença entre esses dois padrões de oferta de serviços.

Outras considerações sobre a opinião dos respondentes estão relacionadas com a faixa etária. Houve significativas correlações entre as opiniões que há diferentes tipos de hospedagem em hotéis empresariais $(0,915)$. Que há realmente uma utilidade de hotéis de projetos para uma qualidade geral de propostas empreendedoras $(0,820)$ e que hotéis de projetos podem ter ofertas tanto em ambientes presenciais quanto virtuais $(0,756)$. 
Tabela 2: Resumo do comparativo de características HP e HE.

\begin{tabular}{|l|l|c|}
\hline Hotel Empresarial & Hotel de Projetos & Resultado \\
\hline $\begin{array}{l}\text { Uma estrutura de serviços de um hotel } \\
\text { empresarial deve favorecer principalmen- } \\
\text { te: encontros corporativos, negociação, } \\
\text { eventos e acomodação. }\end{array}$ & - & $\begin{array}{c}\text { Suportado com 0,997 de corre- } \\
\text { lação para as discriminantes } \\
\text { amostrais "gênero"; "idade". }\end{array}$ \\
\hline $\begin{array}{l}\text { Hotéis empresariais podem acomodar } \\
\text { desde empresários isoladamente a equipes } \\
\text { de empresas simultaneamente. }\end{array}$ & - & $\begin{array}{l}\text { Suportado com 0,951 e 0,915 de } \\
\text { correlação para as discriminantes } \\
\text { amostral "idade". }\end{array}$ \\
\hline- & $\begin{array}{l}\text { Hotéis de projetos são } \\
\text { direcionados para a ativi- } \\
\text { dade empreendedora, } \\
\text { hospedando proponentes } \\
\text { de ideias para novos } \\
\text { negócios. }\end{array}$ & $\begin{array}{l}\text { Suportado com 0,899 e 0,820 de } \\
\text { correlação para as discriminantes } \\
\text { amostrais "gênero"; "idade". }\end{array}$ \\
\hline - & $\begin{array}{l}\text { Hotéis de projetos po- } \\
\text { dem contribuir com a } \\
\text { qualidade e consistência } \\
\text { de planos de negócios. }\end{array}$ & $\begin{array}{c}\text { Suportado com 0,757 de corre- } \\
\text { lação para as discriminantes } \\
\text { amostrais "gênero"; "idade". }\end{array}$ \\
\hline
\end{tabular}

Fonte: Informação adaptada de Machado, Nagem e Lima, 2015.

Observa-se que a discriminante "objetivos para graduação" não oferece graus de correlação para os padrões de resposta da amostra pesquisada. Apenas "gênero" combinado com "idade" ou apenas "idade" é que servem como discriminantes de resposta, em que se percebem correlações consistentes de respostas com níveis de similaridade consistentes.

Tabela 3: Resumo do comparativo HP x HE

\begin{tabular}{|c|c|c|}
\hline $\begin{array}{c}\text { Semelhanças } \\
\begin{array}{c}\text { Hotéis de projetos e hotéis em- } \\
\text { presariais são semelhantes na sua } \\
\text { concepção de favorecimento de } \\
\text { novos negócios. }\end{array}\end{array}$ & $\begin{array}{c}\text { Resultado } \\
\text { correlação para a discriminan- } \\
\text { te amostral "homens"; "ida- } \\
\text { de". }\end{array}$ \\
\hline- & $\begin{array}{c}\text { Hotéis de projetos e hotéis empresa- } \\
\text { rias são diferentes na sua forma de } \\
\text { gerenciamento e administração. }\end{array}$ & $\begin{array}{c}\text { Suportado com 0,976 de } \\
\text { correlação para a discriminan- } \\
\text { te amostral "homens" }\end{array}$ \\
\hline $\begin{array}{c}\text { Hotéis de projetos podem ser pre- } \\
\text { senciais ou virtuais, quando hotéis } \\
\text { empresariais podem ser apenas } \\
\text { presenciais. }\end{array}$ & $\begin{array}{c}\text { Suportado com 0,756 de } \\
\text { correlação para a discriminan- } \\
\text { te amostral "idade". }\end{array}$ \\
$\begin{array}{c}\text { Hotéis de projetos podem se } \\
\text { disponíveis em um hotel empre- } \\
\text { sarial, tais como salas de reuni- } \\
\text { oes, serviços de recados, ambien- } \\
\text { te wi-fi, acomodações privadas, } \\
\text { recepção e segurança. }\end{array}$ & - & $\begin{array}{c}\text { Não Suportado com 0,517 e } \\
\text { 0,287 de correlação para as } \\
\text { discriminantes amostrais } \\
\text { "homens"; "idade". }\end{array}$ \\
\hline
\end{tabular}

Fonte: Informação adaptada de Machado, Nagem e Lima, 2015.

De acordo com essas considerações não foram observadas correlações entre o gênero feminino e os padrões de respostas com baixos coeficientes de correlação, bem como os questionamentos sobre serviços equivalentes entre hotéis empresariais e hotéis de projetos, sobre uma aplicabilidade de hotéis de projetos inteiramente virtual e sobre uma diferença entre ofertas de hotéis de lazer e hotéis empresariais. 


\section{Reflexões e Possibilidades}

Dada as características da amostra e pela confirmação da pouca familiaridade, os graus de correlação apresentados entre essas respostas e pelos aglomerados calculados e apresentados no gráfico 01 abaixo, indicam que é útil essa associação entre o que representa um hotel empresarial para os negócios e um hotel de projetos. Já que são apresentados dois grandes conglomerados, sendo o primeiro destes relacionado com a aproximação de respostas do perfil e o outro sustentado pela aproximação de respostas (coerência) entre as analogias propostas.

Entre as comparações de ofertas de hotéis empresariais e hotéis de projetos, de forma surpreendentemente, os respondentes dessa pesquisa foram coerentes nas suas respostas. Mesmo sem apresentarem conhecimento profundo do "alvo" o "veículo" utilizado se mostrou consistente para um detecção dos pontos chaves que envolvem um hotel de projeto. Dentro de uma abordagem MECA, pode-se perceber que futuras reflexões de significado e retenção de resultados de interação e experiência serão viabilizados pela conscientização dos alunos quanto às similaridades reconhecidas, mesmo sem um repertório ideal.

Figura 01: Conglomerados dos respondentes

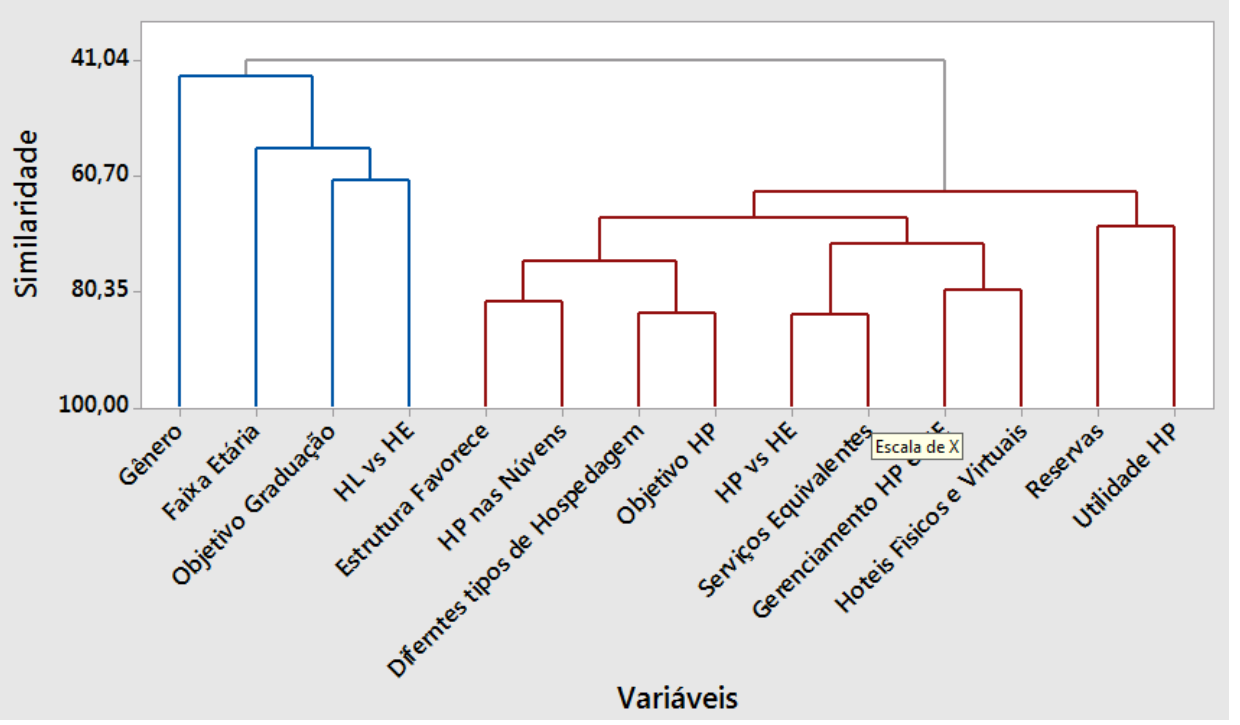

$\mathrm{HL}=$ Hotel de Lazer; HE=Hotel Empresarial; HP=Hotel de Projetos.

Fonte: Machado, Nagem e Lima, 2015.

\section{Considerações Finais}

Após a verificação dos resultados da pesquisa aplicada, observa-se que existem condições favoráveis à manutenção da oferta do núcleo de ensino e extensão voltado para empreendedorismo, não apenas por um interesse dos alunos da disciplina de Empreendedorismo, mas baseado na qualidade das respostas verificadas nessa pesquisa, que direcionam para aspectos de familiaridade e concepção lógica de benefícios.

Esforços de comunicação e contato do núcleo devem recair sobre uma tentativa de aproximação com o perfil de alunos indicado nesses resultados, mas sem se afastar dos mais jovens ou do público feminino, bem como uma manutenção de linha de comunicação com reforço às variáveis similares encontradas entre hotel empresarial e hotel de projeto, já que foram sustentadas pelos resultados da pesquisa. Pelo confirmado, Hotel Empresarial é uma concepção, embora não utilizada pelos alunos, útil para compreensão do que venha a ser Hotel de Projetos.

Sobre a pergunta problema, tem-se que as interseções entre hotéis empresariais foram assimiladas, repercutindo numa percepção de similaridade por parte dos alunos alvo dessa pesquisa. Ao serem confrontados com variáveis de similaridade e de diferenças existentes entre ambas ofertas, 
houve uma constatação de reconhecimento do "alvo" e de adequação dos padrões de resposta, o que sugere que o "alvo" e o "veículo" estão alinhados.

Futuramente, deve-se ampliar ainda mais o resgate da satisfação dos usuários desse núcleo de ensino e extensão, sobretudo com a finalização dos primeiros projetos (3) que estão sendo preparados dentro do Hotel de Projetos, como forma de validar o interesse na oferta de mais acomodações ou inscrições de novos projetos. Ou ainda, novas pesquisas, que possam se servir de analogias e metáforas, voltadas para o ensino e aprendizagem de Administração, sejam utilizadas junto a futuras intervenções metodológicas, como essa pesquisada, relacionadas com avanços e técnicas num intuito de melhor aproveitamento acadêmico.

Do ponto de vista hotel de projetos como atividade extensionista, essa pesquisa ainda guarda um campo potencial de informações pertinentes aos usuários da comunidade em geral, que não foram relacionados ou acessados, por não haver ainda nenhuma entrada de projetos advindos desse perfil de público alvo. Assim quando possível, sugere-se a descrição do perfil e das opiniões desse grupo de potenciais usuários para confrontação com os resultados aqui obtidos. 


\section{REFERENCIAS}

Abbagnano, N. (1999). Dicionário de filosofia. São Paulo, Brasil: Ed. Martins Fontes.

Andrade, R. O., e Amboni, N. (2004). Gestão de cursos de administração: metodologias e diretrizes curriculares. São Paulo, Brasil: Pearson.

Assmann, H. (1998). Metáforas novas para reencantar a Educação, epistemologia e didática. Piracicaba, Brasil: Ed. UNIMEP,

Cachapuz, A. (1989). Linguagem metafórica e o ensino de ciências. Revista Portuguesa de Educação, 2(3), 117-129.

Coordenadoria de Expansão da Brasil Júnior. (2012). DNA JR..

Dias, R. A., e Leite L. S. (2010). Educação a distância: da legislação ao pedagógico. Petrópolis, Brasil: Vozes,

Draper III, W. H. (2012). O jogo das startups: por dentro da parceria entre investidores de risco e os empreendedores. Rio de Janeiro, Brasil: Editora Elsevier,

Dolabela, F. (2004). Pedagogia empreendedora. Revista de negócios Blumenau, 9(2), 127-130.

Dornelas, J. C. A. (2001). Empreendedorismo: transformando ideias em negócios. Rio de Janeiro, Brasil: Editora Elsevier.

Duit, R. (1991). On the role of analogies and metaphors in learning science. Science Education, 75(6), 649-672.

- On the role of analogies and metaphors in learning science. Revista Portuguesa de Educação, 2(3), 117-129.

Fallgatter, M. G. H., e Sena, A. (2004). Papel das Pré-Incubadoras de Empresas no Desenvolvimento do Empreendedorismo: o Caso do Gene-Blumenau. Anais $2^{\circ}$ Congresso Brasileiro de Extensão Universitária. Belo Horizonte, Brasil. Disponível em: https://www.ufmg.br/congrext/Tecno/Tecno9.pdf. Acessado em 20/12/2014

Ferreira, M. P., Santos, J. C., Serra, F. R. (2010). Ser empreendedor: pensar criar e moldar a nova empresa. Lisboa, Portugal: Sílabo.

Gil, A. C. (2012). Didática do ensino superior. São Paulo, Brasil: Atlas.

Goulart, I. B., Papa Filho, S. (2004). Empreendedorismo e empreendedores, sugestão para a educação. Belo Horizonte, Brasil: Editora Newton Paiva.

Grando, N. (Org.). (2012). Empreendedorismo inovador: como criar startups de tecnologia no Brasil. São Paulo, Brasil: Editora Évora.

Grossi, M. G. R., Costa, J. W., e Guimarães, M. B. M. (2013). Concepção construtivista permeada pelo uso de tecnologias: um estudo de caso. Revista Ibero-Americana de Estudos em Educação, 8, 378-393.

Grossi, M. G. R., Costa, J. W., e Moreira, M. M. (2013). O papel do tutor virtual na educação a distância. Revista do Centro de Educação, 38, 659-679.

Hisrich, R. D., Peters, M. P., e Shepherd, D. A. (2009). Empreendedorismo. Porto Alegre, Brasil: Bookman.

Lei 9394/1996, Capítulo IV: Da Educação superior, Arto. 43.VII. Diário Oficial da União, Brasília, Brasil, 20 de dezembro de 1996.

Maia, C., e Mattar, J. (2007). ABC da EaD. São Paulo, Brasil: Pearson Prentice Hall.

Malhotra, N. (2001). Pesquisa de marketing. Porto Alegre, Brasil: Bookman.

Mello, G., e Goldenstein, M. (2011). Perspectivas da hotelaria no Brasil. Brasília, Brasil: Banco Nacional de Desenvolvimento Econômico e Social. Disponível em: https://web.bndes.gov.br/bib/jspui/handle/1408/1509. Acessado em 01/02/2015.

Moran, J. M. (2002). O que é educação a distância. Informe CEAD - Centro de Educação a Distância. Rio de Janeiro, Brasil: SENAI.

Mugnol, M. (2009). A Educação a Distância no Brasil: conceitos e fundamentos. Revista Diálogo Educacional, 9(27), 335-349.

Nagem, R. L., Carvalhaes, D. O., e Dias, J. A.Y. (2001). Uma proposta de metodologia de ensino com analogias. Revista Portuguesa de Educação, 2, 14. 
Nagem, R. L. (1997). Expressão e recepção do pensamento humano e sua relação com o processo de ensino e de aprendizagem no campo da ciência e da tecnologia: imagens, metáforas e analogias. (p. 55). Seminário de Metodologias de Ensino na Área da Educação em Ciência. Concurso Público para o Magistério Superior do Centro Federal de Educação Tecnológica de Minas Gerais, Brasil.

Pocho, C. L., Aguiar, M., Sampaio, M., e Leite, L. (coord.). (2012). Tecnologia educacional: descubra suas possibilidades na sala de aula. Petrópolis, Brasil: Vozes.

Santos, J. R. (2012). A Moodle nas práticas pedagógicas de uma escola básica: realidade ou ficção na inserção das TIC em sala de aula. Educação, Formação \& Tecnologias, 5(1), 72-83.

Wada, E. K., e Camargo, L. O. (2006). Os desafios da hotelaria. Rio de Janeiro, Brasil: GV Executivo.

\section{SOBRE OS AUTORES}

Eduardo B. Machado: Possui graduação em administração de empresas pela Universidade FUMEC (1993). Especialista em Marketing pelo Centro Universitário Newton Paiva e Mestre em Administração com linha em Estratégia Empresarial. Atuou como gerente, supervisor em empresas de distribuição e indústria por 6 anos. Atualmente é consultor empresarial e palestrante. MaGma e CRA MG. Possui obras técnicas publicadas voltadas para a área mercadológica e estratégia, além de resultados de pesquisas. É membro do GEMATEC/AMTEC como professor convidado, cadastrado no $\mathrm{CNPq}$. Atualmente coordenador do curso de graduação tecnológica em Gestão Comercial. Além de professor na graduação da Faculdade Novos Horizontes em MG. Atuou na graduação no Centro Universitário Newton Paiva por 12 anos e é professor credenciado pela Fundação João Pinheiro. Leciona em programas de MBA e Pós Graduação. Linhas de pesquisas: Marketing de serviços; Comportamento dos Consumidores; Competitividade empresarial; Estratégia empresarial; Relações Internacionais e mais recentemente educação, ensino à distância e divulgação de C\&T.

Ronaldo Luiz Nagem: Pós doutor em Educação em Ciências pela Universidade do Minho PT. Doutor e Mestre em Parasitologia pela Universidade Federal de Minas Gerais. Biólogo. Lider do grupo de pesquisa em analogias, metáforas e modelos na tecnologia, na educação e na ciência. Interesse: reconstrução e reprodução de modelos análogos; aplicação da metodologia de ensino com analogias em sala de aula e produção de textos técnicos, científicos e de divulgação científica relacionados às analogias, metáforas e modelos.

Suryam Guimaraes Lima: Estudante de Mestrado em Educação com experiência de atuação laboral em uma escola de educação executiva rankeada pela Financial Times e considerada entre as melhores do mundo. Interesse em temas como: educação profissional, educação a distância, educação executiva, jogos simuladores. Irá trabalhar, na dissertação de mestrado, com Jogos Simuladores como modelos de situações do mercado de trabalho. 